\title{
Developing a Conceptual Model to Evaluate Green Suppliers: Decision Making Method using DEMATEL
}

\author{
Full paper \\ Jay Daniel \\ University of Technology Sydney \\ jay.daniel@uts.edu.au \\ Amir Talaei-Khoei \\ University of Technology Sydney \\ amir.talaei@uts.edu.au
}

\begin{abstract}
Nowadays stakeholder pressure and public awareness have been raised against companies' environmental impacts, so green supply chain management (GSCM) seems vital for companies' environmental compliance and business growth. Companies continuously seek novel ideas and methods enabling them to obtain and/or maintain environmental sustainability. Greening the supply chain is one of such innovative idea involving all of the business value-adding operations, comprising purchasing and in-bound logistics, production and manufacturing, distribution, out-bound logistics and collaboration with patrons and suppliers in a way that has the least negative environmental effect. The main objective of the present study is finding interrelationship between green supplier criteria. For this to happen, we investigated experts' opinions through nominal group technique (NGT) to find out the interrelationship and causal preferences of the green supplier evaluation aspects using Decision-Making Trial and Evaluation Laboratory (DEMATEL) method. A numerical example demonstrates the application of the proposed model.
\end{abstract}

\section{Keywords}

Green Supply Chain Management, Decision-Making Trial and Evaluation Laboratory (DEMATEL)

\section{Introduction}

With growing consciousness of environmental protection worldwide, the green movement towards conserving the earth's resources and protecting the environment is inevitable, compelling on corporations in the world. The pressure accompanying globalization has stimulated enterprises to enhance their environmental performance. Growing environmental importance has gradually incorporated into the overall institutional culture and, in turn, has assisted to re-concentrate the strategies of corporations (Fahimnia et al. 2015; Salam 2008; Zhu and Sarkis 2006).

Companies are under growing competitive and other pressures to continuously seek novel ideas and methods enabling them to obtain and/or maintain environmental sustainability. Greening the supply chain is one such innovative idea that rapidly absorb consideration in the industry and numerous companies. They understand the importance of doing something more than applying traditional internal measures of performing waste-reduction strategies, installing pollution control technologies, substituting environmentally friendly inputs instead of hazardous-material and so on. Various positive influences of internal measures have already been obtained by leading corporations (Fahimnia et al. 2015). Nowadays, the aim has started to shift toward involving all of the business value-adding operations, comprising purchasing and in-bound logistics, production and manufacturing, distribution and out-bound logistics, in such a way with least negative environmental effect (Talaei-Khoei et al. 2011). This is one of the fundamental principles of the philosophy of greening the supply chain that is vital for the prosperous execution of industrial ecosystems and creating value for firms (Bose and Pal 2012).

Additionally, there is another reason why the greening of the supply chain is being widespread within industry. Many world-class companies now perceive that customers and other stakeholders do not point out a difference between a company and its suppliers. According to Bacallan's study (2000), "although they 
may have nothing to do at all with the problem, companies are often held accountable for the labor practices and the environmental liabilities of their suppliers". So, greening the supply chain assists companies to keep away from potential environmental problems that might emerge with their suppliers and that in turn could endanger their own environmental performance. Problems emerging for organizations can extend from actual business continuousness and heavy responsibility issues to intuitive problems of possessing 'dirty' partners (Sarkis 2006).

Although there has been a body of literature evaluating suppliers in the context of green supply chain, an explicated conceptual model that ranks different suppliers from the green supply chain perspective has been largely ignored. For that to happen, Mingbo and Dan (2009) suggested a model that states the criteria of green suppliers' performance. However, the model to be effective a decision making tool lacks the relationships between the constructs of the model and the significance of these relationships.

The main objective of this paper is to (a) come up with the relationships for the Mingbo and Dan (2009)'s model and (2) determine the significance of interrelationships between criteria to evaluate supplier performance. Multi Criteria Decision Making (MCDM) assists organizations and supply chain managers making more effective decisions (Chai et al. 2013). To promote this area of research and to help further integrate sustainability discussion into the suppliers' evaluation modeling area, we model the supplier evaluation problem in green supply chain context with a group decision making approach which is a Decision making trial and evaluation laboratory (DMATEL) method. Since, DMATEL simplifies the complex criteria and recognizes interrelationship influences between factors of green suppliers, we have utilized it to determine the significance of the relationships into our conceptual models.

The rest of this paper is organized in the following way; the first section presents the body of literature in green supply chain. The following section presents the proposed conceptual model. The third section presents the application of DMATEL in determining the significance of the relationships between the criteria of the model. The fourth section demonstrates the proposal using a numerical example. The last section discusses the implications of the work for academics and practitioners as well as pointing out the limitations and the avenues of future work.

\section{Green Supply Chain}

With restricting government regulation and growing public consciousness in environmental protection, companies today definitely cannot neglect environmental issues if they care for surviving in the global market. Besides following the environmental regulations for selling products in particular countries, companies require to execute strategies to voluntarily diminish the environmental effects of their products. The combination of environment, economic and social performances to reach sustainable development is a prominent business challenge for the new century (Verghese and Lewis 2007).

Some possible definitions of Green Supply Chain Management (GSCM), known as a principal in achieving sustainable business development, have been presented over the last decade, are including: (1) Green supply applies to the way in which innovations in supply chain management and industrial purchasing may be taken into consideration in the context of the environment (Green et al. 1996). (2) Environmental supply chain management is composed of the purchasing function's involvement in activities that comprise reduction, recycling, reuse and the substitution of materials (Narasimhan and Carter 1998). (3) GSCM is the practice of monitoring and enhancing environmental performance in the supply chain (Godfrey 1998).

In literature, several researches have been reported which assessed environmental performance of suppliers and supply chains (Govindan et al. 2015). Enarsson (1998) suggested a fish bone diagram to assess environmental features of suppliers. Humphreys and colleagues (2003a) applied case-based reasoning to evaluate environmental performance of suppliers. Bai and Sarkis (2010) employed grey system and rough set methodologies to merge sustainability into supplier selection. Humphreys et al. (2006) took advantages of dynamic fuzzy membership functions to evaluate environmental performance in the supplier selection process. Handfield et al. (2002) applied environmental criteria in AHP for supplier assessment. Tuzkaya and colleagues (2009) demonstrated a hybrid fuzzy multi criteria decision approach for measuring environmental performance assessment of suppliers. Zhang et al. (2003) suggested a fuzzy multi-agent decision-making strategy for environmentally aware supplier management. Noci (1997) suggested 'green' vendor rating systems for evaluating of supplier's environmental performance. Walton et al. (1998a) presented an approach for greening the supply chain by involving suppliers into environmental 
management processes. Lee and co-workers (2009) demonstrated a green supplier selection model for high-tech industry employing Delphi method and fuzzy extended analytic hierarchy process. Lu et al. (2007) suggested a multi-objective decision analysis to use environmental tenets in order to assess green supplier at various levels of supply chain. Humphreys and colleagues (2003b) presented multi-stage framework for combining environmental criteria with supplier selection process and examining suppliers' environmental performance examined against legal needs.

Various multinational enterprises are investing in researching and developing green products, constructing standards avoiding the use of hazardous substances, and instructing suppliers to deliver products that are free of hazardous materials at all levels of the supply chain. Therefore, GSCM has appeared as a strategy for several leading companies in the electronics industry, comprising Dell, HP, IBM, Motorola, Sony, Panasonic, NEC, Fujitsu, and Toshiba (Zhu and Sarkis 2006). This phenomenon indicates that companies are now commencing to identify that environmental consciousness can be an origin of competitive advantage (Bose and Pal 2012; Walton et al. 1998b). In addition, GSCM can encourage efficiency and synergy among business partners and their lead corporations, and assists to improve environmental performance, diminish waste and acquire cost saving (Rao and Holt 2005).

In the present business environment, procurement has turned into be a crucial in creating value-added contents of products and a necessary determining factor to ensure the profitability and survival of a company. The purchasing process gets more complicated when environmental and social issues are involved (Lee et al. 2009). In this context, green supplier evaluation is appearing more essential for effective green supply chain management (Govindan et al. 2015).

Bala and colleagues (2008) investigated five cases of supplier greening at Universitat Autonoma de Barcelona and indicated that collaboration and partnerships with suppliers may promote the introduction of green supply and guarantee the prosperous of a green initiative in a public organization. Jabbour and Jabbour (2009) carried out case studies of Brazilian companies to realize whether supplier selection criteria are becoming green and deduced that a company with more advanced environmental management embraces more formal procedures for choosing environmentally suitable suppliers than others.

\section{AN Analytic Network Supplier Evaluation Model for Green Supply Chain}

Constructing an operative supplier evaluation model is one of the crucial challenges facing by supply chain managers. In order to evaluate potential suppliers, it is required to develop a set of relevant selection criteria. In this sense, quality, cost efficiency, delivery, information, volume, lead time flexibility and customer service level are the traditional criteria (Yeh and Chuang 2011). Some advocated criteria are including innovation, which is the capability of the supplier to provide design and technological capabilities to the customer, supplier location, the willingness of suppliers to share information and legal terms (Aref et al. 2005; Katsikeas et al. 2004). The Analytic Network Supplier Evaluation Model for Green Supply Chain, proposed in this study, suggests that the supplier evaluation criteria fall into six dimensions: competitive pricing and cost, reliability, production capability, service, environmental performance and pollution control. They are examined below and shown in Fig.1. The hierarchy model of green supplier evaluation is shown in figure 1 which is adapted based on Mingbo and Dan (2009).

\section{Proposed Method}

A research design is the logic that links the data collected during the initial questioning of this study. The current research is devoted to the development of a conceptual model for green supplier evaluation using DEMATEL for adapting of uncertainties and complexities in the real world, helping supply chain managers and organizations to find a suitable tool for evaluating and controlling the green suppliers through different approaches. The green supplier evaluation methodology proposed in this study has three main steps as follows:

1-Establishing and analyzing the sustainable criteria for supplier evaluation using experts' opinions with NGT. The expert panel is consisting of five managers and directors of environmental and supply chain departments in five different companies. In this step, the evaluation criteria for green suppliers will be 
collected through literature review and discussion with managers in an industry and eco-experts with NGT based on the analytic network supplier evaluation model for green supply chain which is shown in Figure 1.

2- Modeling DEMATEL for supplier performance evaluation in green supply chain context. In this step, DEMATEL for green supplier evaluation will be designed and provide insights into the method with some sensitivity analysis.

3-Validation of the model: A numerical example will be carried out to validate the new green supplier evaluation method.

Due to the complexity of the decision-making process involved in green supplier evaluation, several aforementioned literatures relied on some form of procedures that assign weights to various performance measures (Talaei-Khoei et al. 2012). Our review shows that although some mathematical programming approaches based on multi-criteria decision making methods have been used for the green supplier evaluation in different studies, they have a main weakness which is their inability to include interrelationships within the criteria in the model. It is often a difficult task for the decision maker to clarify these interrelations and causal preferences. Aim of this paper is to find out the interrelationship of the green supplier evaluation aspects using DEMATEL method.

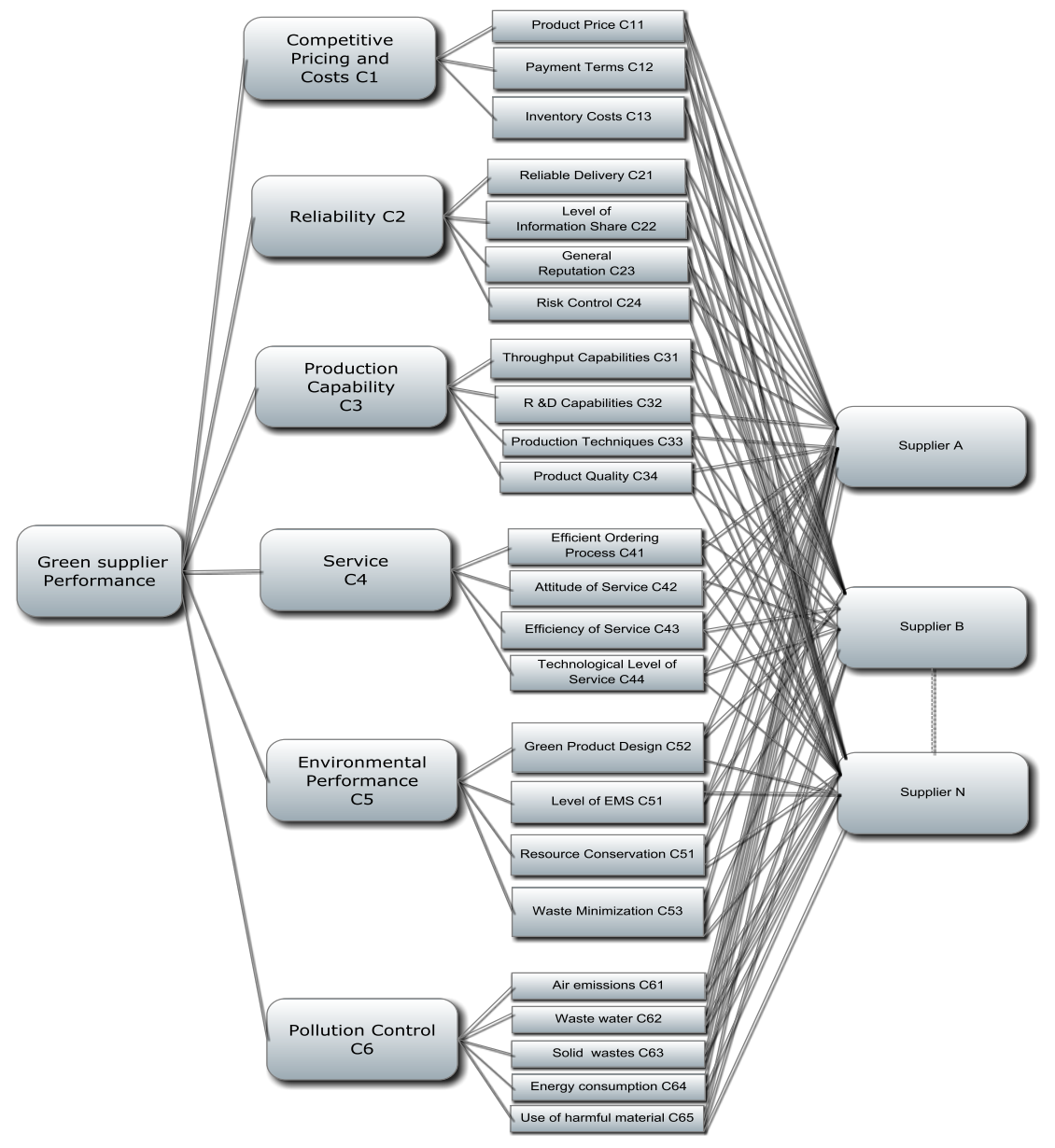

Figure 1: The Analytic Network Supplier Evaluation Model for Green Supply Chain

DEMATEL is a sophisticated group decision making method for formulating and evaluating a structural model comprising the causal relationships among the complex and numerous factors (Lin and Lin 2008). During 1972 to 1976, this method was employed for the first time at Battelle Memorial Institute in Geneva to find out the complicated and interlaced problem group (Gwo-Hshiung et al. 2011). This methodology can verify interrelations between criteria and limit the relations which resonate the attributes of a system 
(Amiri et al. 2011). DEMATEL method has been developed based on the opinion that suitable employ of scientific research methods could improve understanding of certain problems and determine solutions with executive capability by a hierarchical structure (Lin and Lin 2008). Using DEMATEL method for evaluating and processing individuals' perceptions leads to individuals' personal notions being involved in complex problems (Gwo-Hshiung et al. 2011). The final product of DEMATEL process is a visual demonstration - mind map - based on which the respondent manages his/her actions regarding the world (Amiri et al. 2011) or adheres to the priorities stated in it (Gwo-Hshiung et al. 2011).

DEMATEL method consists of few steps which are delineated as follows.

\section{Step 1: Creating the direct-relation matrix}

Five scales are employed to measure the relationship between various criteria comprising:

$\mathrm{o}=$ no influence, 1 = low influence, 2 = medium influence, 3 = high influence, 4 = very high influence

Then sets of the pair-wise comparisons in terms of effects and direction among criteria are provided by decision makers. Thereafter the initial data can be achieved as a direct-relation matrix, which is a [ $\mathrm{n} \times \mathrm{n}]$ matrix A. Each element of aij is marked as the degree in which the criterion $\mathrm{i}$ impresses the criterion $\mathrm{j}$.

\section{Step 2: Normalizing the direct-relation matrix}

Normalization is calculated applying the following equation. Note that each element $x_{i j}$ of matrix $\mathrm{X}$ is maximum one and minimum zero.

$\mathrm{K}=1 /\left(\max _{1<\mathrm{i}<\mathrm{n}} \sum_{\mathrm{j}=1} \mathrm{a}_{\mathrm{ij}}\right) \quad \mathrm{i}, \mathrm{j}=1,2, \ldots, \mathrm{m}$
$\mathrm{X}=\mathrm{K} \times \mathrm{M}$

\section{Step 3: Calculating the total-relation matrix}

By applying the following formula (2), the total-relation matrix will be calculated. Note that I is the $m \times m$ identity matrix.

$T=X(I-X)^{-1}$

\section{Step 4: Generating a causal diagram}

Through Equation 3, the sum of rows and the sum of columns are separately marked as vector D and vector R. Afterwards, the horizontal axis vector $(D+R)$, called "Prominence", is created by adding $D$ to $R$, which presents the relative importance for every criterion. Likewise, the vertical axis (D-R), called "Relation", is generated by subtracting $\mathrm{D}$ from $\mathrm{R}$, which may categorize criteria into two groups including cause and effect. In general, the positive (D-R) means the criterion lies in the cause group and the negative (D-R) means the criterion reveals the effect group. Hence, the causal diagram is achievable by mapping the dataset of the (D+R, D-R), revealing some insight for facilitating decision makings.

$T=\left[t_{i j}\right]_{m \times m} \quad i, j=1,2, \ldots, m$

$D=\left[\sum_{j=1}^{m} t_{i j}\right]_{m \times 1}=\left[t_{i,}\right]_{m \times 1}$

$R=\left[\sum_{i=1}^{m} t_{i j}\right]_{1 \times m}=\left[t_{s j}\right]_{1 \times m}$

\section{Numerical example}

NGT is a method for making decision applicable among different group sizes, in order to speed making decision, as by a vote, but everyone's opinions are considered and taken into account. There was an interview with experts of green supply chain. It is vital to search out experts who will verify the relationships among the influential success factors of green supplier performance. Experts were asked to 
organize sets of pair-wise comparisons in terms of impacts and direction among green supplier performance factors including six dimensions: competitive pricing and cost, reliability, production capability, service, environmental performance and pollution control. So the initial information can be achieved as a direct-relation matrix which could be a $6 \times 6$ matrix A, where every element of Xij is marked as the degree, within that the element i influences the element $\mathrm{j}$. At this stage, we can notice the relation among significant factors in every criterion. Causal diagram which incorporates horizontal maxis (D+R) and vertical axis (D-R) is ready. Relative importance of every feature is shown in horizontal axis, referring to "Prominence" similarity features which are divided into cause and effect clusters in vertical axis and are called "Relation". Besides, advanced causal relationships aspects are visualized into observable structural model by causal diagram. However, if (D-R) is negative, this facet lies in the effect group; alternatively, if (D-R) is positive, the facet lies in the cause cluster. The relative importance of criteria is set by committee of professional decision makers. The relations among essential factors which are proposed in modeling of green supplier performance are illustrated in Figure 1.

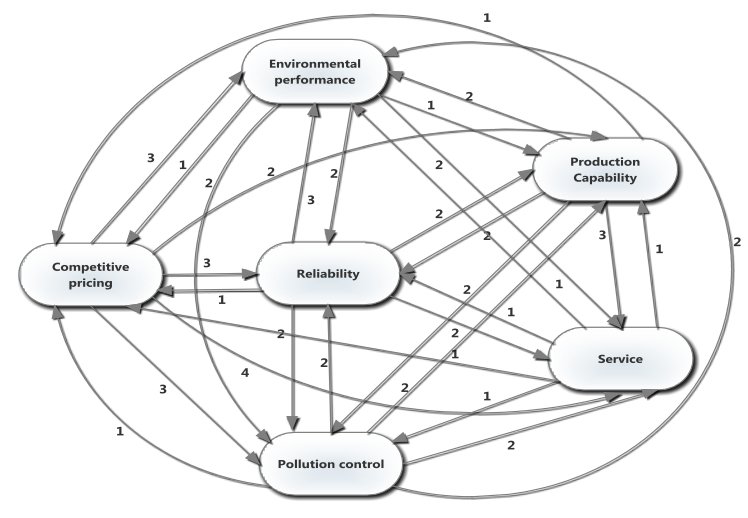

Figure 1. The relationships in green supplier performance

On the basis of step 2 and equation 1 normalized matrix of green supplier performance evaluation is depicted as follows (Table 1).

\begin{tabular}{|c|c|c|c|c|c|c|}
\hline Normalized matrix & $\begin{array}{c}\text { Competitive } \\
\text { pricing }\end{array}$ & Reliability & $\begin{array}{c}\text { Production } \\
\text { Capability }\end{array}$ & Service & $\begin{array}{c}\text { Environmental } \\
\text { performance }\end{array}$ & $\begin{array}{r}\text { Pollution } \\
\text { control }\end{array}$ \\
\hline Competitive pricing & 0 & 0.2 & 0.1333 & 0.2667 & 0.2 & 0.2 \\
\hline Reliability & 0.0667 & $\mathrm{O}$ & 0.1333 & 0.1333 & 0.2 & 0.1333 \\
\hline Production Capability & 0.0667 & 0.1333 & 0 & 0.2 & 0.1333 & 0.1333 \\
\hline Service & 0.0667 & 0.0667 & 0.0667 & 0 & 0.0667 & 0.0667 \\
\hline Environmental performance & 0.0667 & 0.1333 & 0.0667 & 0.1333 & $\mathrm{O}$ & 0.1333 \\
\hline Pollution control & 0.0667 & 0.1333 & 0.1333 & 0.1333 & 0.1333 & 0 \\
\hline
\end{tabular}

Table 1. Normalized green supplier performance evaluation

Then DEMATEL technique and total relationships matrix are applied to green supplier performance evaluation; important factors for green supplier performance evaluation are demonstrated in Tables 2.

\begin{tabular}{|c|c|c|c|c|c|c|c|}
\hline Criteria & $\begin{array}{l}\text { Competitive } \\
\text { pricing }\end{array}$ & Reliability & $\begin{array}{c}\text { Production } \\
\text { Capability }\end{array}$ & Service & $\begin{array}{c}\text { Environmental } \\
\text { performance }\end{array}$ & $\begin{array}{c}\text { Pollution } \\
\text { control }\end{array}$ & $\mathrm{R}$ \\
\hline Competitive pricing & 0.1459 & 0.4273 & 0.3333 & 0.5465 & 0.4525 & 0.4273 & 2.3328 \\
\hline Reliability & 0.1635 & 0.1794 & 0.2659 & 0.3425 & 0.3665 & 0.2971 & 1.6149 \\
\hline Production Capability & 0.1619 & 0.2911 & 0.1458 & 0.391 & 0.3082 & 0.2911 & 1.5891 \\
\hline Service & 0.1182 & 0.163 & 0.1459 & 0.1272 & 0.1726 & 0.163 & 0.8899 \\
\hline $\begin{array}{l}\text { Environmental } \\
\text { performance }\end{array}$ & 0.1454 & 0.2644 & 0.1875 & 0.3017 & 0.1623 & 0.2644 & 1.3257 \\
\hline Pollution control & 0.1549 & 0.2815 & 0.2549 & 0.3247 & 0.2981 & 0.1639 & 1.478 \\
\hline $\mathrm{D}$ & 0.8898 & 1.6067 & 1.3333 & 2.0336 & 1.7602 & 1.6068 & \\
\hline $\mathrm{D}+\mathrm{R}$ & 3.2226 & 3.2216 & 2.9224 & 2.9235 & 3.0859 & 3.0848 & \\
\hline D-R & -1.443 & -0.0082 & -0.2558 & 1.1437 & 0.4345 & 0.1288 & \\
\hline
\end{tabular}


Table 2. Total relationships matrices for green supplier performance evaluation Discussion, Conclusion and Future Work

In group decision making problems, often complex criteria are encountered which either influence, called cause group, or are influenced by several other criteria, making the effect group. Improvement in one or two criteria necessarily does not result in the overall system improvement, since there is a dependence and feedback relationship among the criteria. To make an effective decision, first cause group criteria need to be recognized and improved which leads to the effect group criteria improvement.

As discussed above, DEMATEL methodology was applied in this study to explore the interactions among multiple criteria, which filled the gap left by traditional models. In fact, traditional models set strategies by only considering direct effects or single directions of criteria (Horng et al. 2013).

Final results that indicate influence levels of each criterion in the system as well as on each other are presented in Table 2. On the basis of the ' $\mathrm{D}$ - R' values, the criteria are categorized into two groups as cause and effect groups. The criteria Service, Environmental performance and Pollution control fall under the cause group for having positive 'D - R' values. The criteria having negative ' $D$ - R' values are categorized as effect group criteria, which include criteria Competitive pricing, Reliability and Production Capability. The results of cause and effect analysis show that 'competitive pricing' which belongs to effect group is the most important criterion in this group. This result is in line with the findings of Rao and Holt (2005) which shows that integrated green supply chain ultimately leads to competitiveness and economic performance.

Through the analysis of the ' $\mathrm{R}+\mathrm{D}$ ' values it is also found that the criterion competitive pricing is the most important driver among all criteria. The result is supported by the argument that competitive pricing about GSCM benefits is necessary to elicit their commitment and support for implementation of GSCM. Without competitive pricing, it would be difficult to order required resources for GSCM implementation. In addition, competitive pricing provides an opportunity of preparing the environmental policy of an organization and creating the GSCM implementation plan. Following the confirmation of competitive pricing, ' $\mathrm{R}+\mathrm{D}$ ' values of other criteria are investigated to evaluate their priorities. The criteria, according to their degree importance were identified as Reliability $>$ Environmental performance $>$ Pollution control $>$ Service $>$ Production Capability. The result demonstrates that environmental performance as the third most important criterion is a suitable indictor for displaying companies adopting their supply chain into the GSCM. The results of the priority weight analysis of the criteria show that the 'Production Capability' has less influence on GSCM adoption. The facts show that production capability falls under effect group and there is a causal relationship between green design and production capability.

The results also illustrate that two of the criteria from cause group, 'environmental performance' and 'pollution control' are prioritized as the first and second key criteria, respectively. Two main reasons are suggested for higher influence of 'environmental performance' on GSCM adoption by the industries. First, societal concern for environmental protection saying that the regulations, stakeholder pressures and public awareness raised against the environmental impacts (Fahimnia et al. 2015; Sarkis 2006). Second, greening the different phases of the supply chain results in an integrated green supply chain, which eventually trigger competitiveness and economic performance (Bose and Pal 2012; Rao and Holt 2005).

\section{Implications for Academics}

As public awareness is raised against environmental protection in the world, a huge response to a green trend in conservation of natural resources and protection of the environment is risen, thereby enforcing industries around the world ( $\mathrm{Xu}$ et al. 2013). Eventually, these happenings lead to development and adoption of numerous environmental management techniques by companies from different industrial sectors around the world. Among all strategies, GSCM is becoming popular due to its ability of improving environmental performance of the entire supply chain. Previous studies demonstrated improvement in organizational performance through improved environmental supply (Walker et al. 2008). Although GSCM's importance and its benefits are well known, it has not been commonly accepted, due to a poor understanding of diverse influential factors of GSCM and the interdependence. These influential factors can be divided in barriers and drivers. Barriers offer resistance to GSCM implementation (Muduli et al. 2013). Drivers differ according to their strength of influence on each other and on the entire system. 
DEMATEL method was proposed in this research to evaluate the direct and indirect influences of GSCM criteria. DEMATEL technique helps the decision-making process to assess the causal relationship and the influence/strength of the target system criteria and displays the direct and indirect influences of criteria through a visual diagram (Govindan et al. 2016). In this study, the hierarchy model of green supplier evaluation adapted based on Mingbo and Dan (2009) which include six criteria and analyzed by DEMATEL method. The analysis result was divided into two parts. First, the degree of influence of each criterion (priority weight) on the system was assessed and applied as a basis for ranking them. Secondly, the criteria were categorized as the net dispatcher (cause group) criterion or net receiver (effect group) criteria. The cause group criteria not only have higher driving power of the entire system, but also a strong influence on the effect group criteria. Indeed, the improvement in criteria of the cause group will result in improvement in the criteria of the effect group. Therefore, the study finds that the environmental performance and pollution control as cause group criteria have great influence on competitive pricing and reliability criteria, according to the priority weight analysis. Since, DMATEL simplifies the complex criteria and recognize interrelationship influences between factors of green suppliers, this study has several particular contributions including, 1) Determining the explicit criteria and sub-criteria and interrelationship between them regarding all factors of competitive pricing and cost, reliability, production capability, service, environmental performance and pollution control for balancing greening supply chain issues. 2) Modeling the DEMATEL for determining interrelationship between criteria to evaluate supplier performance. 3) Developing a practical model in green supply chain context which can help organizations and supply chain managers make more effective decisions.

\section{Implications for Practitioners}

Using DEMATEL in this study provides easier way to find the complexity of the decision making problem through classifying the complex criteria into cause and effect groups, thereby helping to facilitate important decision making. The managerial implications that extracted from this study are:

- Categorization of criteria into cause and effect group will assist the decision makers to determine the group of factors (cause group) requiring control and attention (Lin 2013). In fact, cause group criteria are difficult to move while those included in effect group are easily moved (Govindan et al. 2016). Additional prioritization of the criteria will assist the decision makers in identifying the criteria requiring improvement on a priority basis, which subsequently improves other criteria and the entire system.

- Table 2 and Fig 1 (cause and effect diagram) illustrated that competitive pricing is the most important criterion in the ranking. Obviously, it has the highest ' $R$ ' value which is an indication of the highest degree of influence allotted by it on other criteria and on the system (Akhilesh and Kamalakanta 2013).

- It has been shown that 'pollution control' is the fourth most significant criterion. It is fall under the cause group category and also has the highest driving power in this group due to its highest value of ' $R$ '. Therefore, managers should concentrate on pollution control and environmental performance to improve GSCM performance. Furthermore, they should aim at formulating strategies that concentrate on fulfilling pollution requirements for enhanced environmental performance for balancing economic and environment indicators (Wu and Pagell 2011).

\section{Limitations and Future Work}

Analysis of GSCM criteria with DEMATEL method is performed using the judgment of few experts. However, for constructing a solid model, future studies should include a network base data envelopment analysis model. Although, some methods have been developed with a variety of formal modeling techniques, they may be limited due to different reasons. Multi Criteria Decision Making (MCDM) methods and decision support tools and methodologies can assist organizations and supply chain managers make more effective decisions. To promote this area of research and to help further integrate sustainability discussion into the suppliers' evaluation modeling area, future studies might aim modelling the supplier evaluation problem in green supply chain context with a novel approach which first introduced by Charnes (1978). This approach employs Network Data Envelopment Analysis, a relatively new "data oriented" approach, for assessing the performance of a set of peer entities, named Decision Making Units (DMUs), turning multiple inputs into multiple outputs (Cook and Zhu 2005; Kao 2009). 


\section{REFERENCES}

Akhilesh, B., and Kamalakanta, M. 2013. "Modelling the Challenges of Green Supply Chain Management Practices in Indian Mining Industriesnull," Journal of Manufacturing Technology Management (24:8), pp. 1102-1122.

Amiri, M., Sadaghiyani, J. S., Payani, N., and Shafieezadeh, M. 2011. "Developing a Dematel Method to Prioritize Distribution Centers in Supply Chain," Management Science Letters (1:3), pp. 279-288.

Aref, A. H., Marilyn, M. H., and Joseph, S. 2005. "Performance Measurement for Green Supply Chain Management," Benchmarking: An International Journal (12:4), pp. 330-353.

Bacallan, J. 2000. "Greening the Supply Chain," Business and Environment (6:5), pp. 11-12.

Bai, C., and Sarkis, J. 2010. "Integrating Sustainability into Supplier Selection with Grey System and Rough Set Methodologies," International Journal of Production Economics (124:1), pp. 252-264.

Bala, A., Munoz, P., Rieradevall, J., and Ysern, P. 2008. "Experiences with Greening Suppliers. The Universitat Autonoma De Barcelona," Journal of Cleaner Production (16:15), pp. 1610-1619.

Bose, I., and Pal, R. 2012. "Do Green Supply Chain Management Initiatives Impact Stock Prices of Firms?," Decision Support Systems (52:3), pp. 624-634.

Chai, J., Liu, J. N., and Ngai, E. W. 2013. "Application of Decision-Making Techniques in Supplier Selection: A Systematic Review of Literature," Expert Systems with Applications (40:10), pp. 3872-3885.

Charnes, W. 1978. "Measuring the Efficiency of Decision Making Units* 1," European journal of operational research (2:6), pp. 429-444.

Cook, W., and Zhu, J. 2005. Modeling Performance Measurement: Applications and Implementation Issues in Dea. Springer Verlag.

Enarsson, L. 1998. "Evaluation of Suppliers: How to Consider the Environment," International Journal of Physical Distribution \& Logistics Management (28:1), pp. 5-17.

Fahimnia, B., Sarkis, J., and Davarzani, H. 2015. "Green Supply Chain Management: A Review and Bibliometric Analysis," International Journal of Production Economics (162), pp. 101-114.

Godfrey, R. 1998. "Ethical Purchasing: Developing the Supply Chain Beyond Environment," Greener purchasing: Opportunities and innovations), pp. 244-251.

Govindan, K., Muduli, K., Devika, K., and Barve, A. 2016. "Investigation of the Influential Strength of Factors on Adoption of Green Supply Chain Management Practices: An Indian Mining Scenario," Resources, Conservation and Recycling (107), pp. 185-194.

Govindan, K., Rajendran, S., Sarkis, J., and Murugesan, P. 2015. "Multi Criteria Decision Making Approaches for Green Supplier Evaluation and Selection: A Literature Review," Journal of Cleaner Production (98), pp. 6683.

Green, K., Morton, B., and New, S. 1996. "Purchasing and Environmental Management: Interactions, Policies and Opportunities," Business Strategy and the Environment (5:3), pp. 188-197.

Gwo-Hshiung, T., Tzeng, G.-H., and Huang, J.-J. 2011. Multiple Attribute Decision Making: Methods and Applications. CRC Press.

Handfield, R., Walton, S., Sroufe, R., and Melnyk, S. 2002. "Applying Environmental Criteria to Supplier Assessment: A Study in the Application of the Analytical Hierarchy Process," European Journal of Operational Research (141:1), pp. 70-87.

Horng, J.-S., Liu, C.-H., Chou, S.-F., and Tsai, C.-Y. 2013. "Creativity as a Critical Criterion for Future Restaurant Space Design: Developing a Novel Model with Dematel Application," International Journal of Hospitality Management (33), pp. 96-105.

Humphreys, P., McCloskey, A., McIvor, R., Maguire, L., and Glackin, C. 2006. "Employing Dynamic Fuzzy Membership Functions to Assess Environmental Performance in the Supplier Selection Process," International Journal of Production Research (44:12), pp. 2379-2419.

Humphreys, P., McIvor, R., and Chan, F. 2003a. "Using Case-Based Reasoning to Evaluate Supplier Environmental Management Performance," Expert Systems with Applications (25:2), pp. 141-153.

Humphreys, P. K., Wong, Y. K., and Chan, F. T. S. 2003b. "Integrating Environmental Criteria into the Supplier Selection Process," Journal of Materials Processing Technology (138:1-3), pp. 349-356.

Jabbour, A., and Jabbour, C. 2009. "Are Supplier Selection Criteria Going Green? Case Studies of Companies in Brazil," Industrial Management \& Data Systems (109:4), pp. 477-495.

Kao, C. 2009. "Efficiency Decomposition in Network Data Envelopment Analysis: A Relational Model," European Journal of Operational Research (192:3), pp. 949-962.

Katsikeas, C. S., Paparoidamis, N. G., and Katsikea, E. 2004. "Supply Source Selection Criteria: The Impact of Supplier Performance on Distributor Performance," Industrial Marketing Management (33:8), pp. 755-764. 
Lee, A., Kang, H., Hsu, C., and Hung, H. 2009. "A Green Supplier Selection Model for High-Tech Industry," Expert Systems with Applications (36:4), pp. 7917-7927.

Lin, K.-m., and Lin, C.-w. 2008. "Cognition Map of Experiential Marketing Strategy for Hot Spring Hotels in Taiwan Using the Dematel Method," Natural Computation, 2008. ICNC'08. Fourth International Conference on: IEEE, pp. 438-442.

Lin, R.-J. 2013. "Using Fuzzy Dematel to Evaluate the Green Supply Chain Management Practices," Journal of Cleaner Production (40), pp. 32-39.

Lu, L., Wu, C., and Kuo, T. 2007. "Environmental Principles Applicable to Green Supplier Evaluation by Using Multi-Objective Decision Analysis," International Journal of Production Research (45:18), pp. 4317-4331.

Mingbo, S., and Dan, Y. 2009. "Integrating Environmental Performance into the Supplier Evaluation: A Gra-Based Method," Industrial Engineering and Engineering Management, 2009. IE\&EM '09. 16th International Conference on, pp. 162-166.

Muduli, K., Govindan, K., Barve, A., and Geng, Y. 2013. "Barriers to Green Supply Chain Management in Indian Mining Industries: A Graph Theoretic Approach," Journal of Cleaner Production (47), pp. 335-344.

Narasimhan, R., and Carter, J. R. 1998. Environmental Supply Chain Management. Tempe, Ariz.: Center for Advanced Purchasing Studies.

Noci, G. 1997. "Designing 'Green' Vendor Rating Systems for the Assessment of a Supplier's Environmental Performance," European Journal of Purchasing \& Supply Management (3:2), pp. 103-114.

Rao, P., and Holt, D. 2005. "Do Green Supply Chains Lead to Competitiveness and Economic Performance?," International Journal of Operations \& Production Management (25:9), pp. 898-916.

Salam, M. A. 2008. "An Empirical Investigation of the Determinants of Adoption of Green Procurement for Successful Green Supply Chain Management," Management of Innovation and Technology, 2008. ICMIT 2008. 4th IEEE International Conference on, pp. 1038-1043.

Sarkis, J. 2006. Greening the Supply Chain. Berlin; London: Springer.

Talaei-Khoei, A., Solvoll, T., Ray, P., and Parameshwaran, N. 2011. "Policy-Based Awareness Management (Pam): Case Study of a Wireless Communication System at a Hospital," Journal of Systems and Software (84:10), pp. 1791-1805.

Talaei-Khoei, A., Solvoll, T., Ray, P., and Parameshwaran, N. 2012. "Maintaining Awareness Using Policies; Enabling Agents to Identify Relevance of Information," Journal of Computer and System Sciences (78:1), pp. 370-391.

Tuzkaya, G., Ozgen, A., Ozgen, D., and Tuzkaya, U. 2009. "Environmental Performance Evaluation of Suppliers: A Hybrid Fuzzy Multi-Criteria Decision Approach," International Journal (6:3), pp. 477-490.

Verghese, K., and Lewis, H. 2007. "Environmental Innovation in Industrial Packaging: A Supply Chain Approach," International Journal of Production Research (45:18), pp. 4381-4401.

Walker, H., Di Sisto, L., and McBain, D. 2008. "Drivers and Barriers to Environmental Supply Chain Management Practices: Lessons from the Public and Private Sectors," Journal of Purchasing and Supply Management (14:1), pp. 69-85.

Walton, S., Handfield, R., and Melnyk, S. 1998a. "The Green Supply Chain: Integrating Suppliers into Environmental Management Processes," International Journal of Purchasing and Materials Management (34), pp. 2-11.

Walton, S. V., Handfield, R. B., and Melnyk, S. A. 1998b. "The Green Supply Chain: Integrating Suppliers into Environmental Management Processes," Journal of Supply Chain Management (34:2), pp. 2-11.

Wu, Z., and Pagell, M. 2011. "Balancing Priorities: Decision-Making in Sustainable Supply Chain Management," Journal of Operations Management (29:6), pp. 577-590.

Xu, L., Mathiyazhagan, K., Govindan, K., Noorul Haq, A., Ramachandran, N. V., and Ashokkumar, A. 2013. "Multiple Comparative Studies of Green Supply Chain Management: Pressures Analysis," Resources, Conservation and Recycling (78), pp. 26-35.

Yeh, W.-C., and Chuang, M.-C. 2011. "Using Multi-Objective Genetic Algorithm for Partner Selection in Green Supply Chain Problems," Expert Systems with Applications (38:4), pp. 4244-4253.

Zhang, H., Li, J., and Merchant, M. 2003. "Using Fuzzy Multi-Agent Decision-Making in Environmentally Conscious Supplier Management," CIRP Annals-Manufacturing Technology (52:1), pp. 385-388.

Zhu, Q., and Sarkis, J. 2006. "An Inter-Sectoral Comparison of Green Supply Chain Management in China: Drivers and Practices," Journal of Cleaner Production (14:5), pp. 472-486. 